\title{
OTX2 stimulates adult retinal ganglion cell regeneration
}

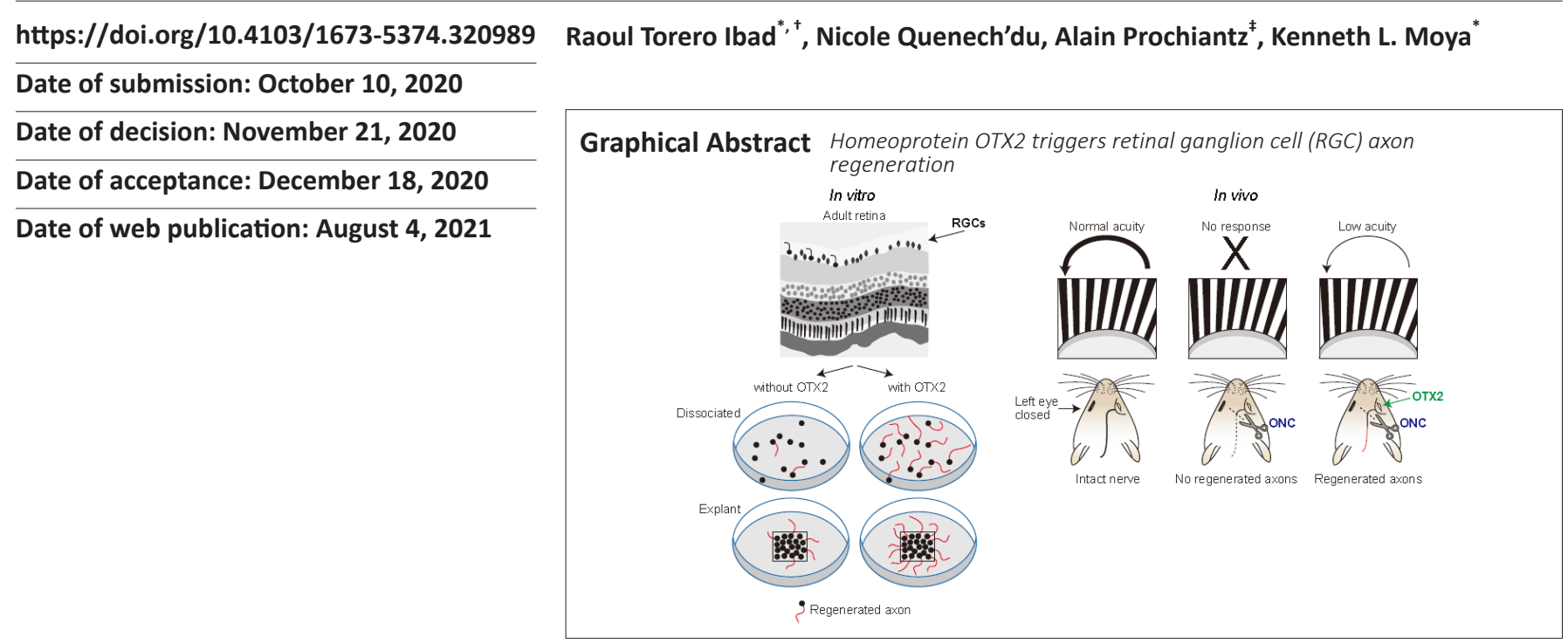

\begin{abstract} cell

Chinese Library Classification No. R459.9; R364; R774

\section{Introduction}

Neurodegenerative diseases that affect retinal ganglion cells (RGCs) lead to a degradation of vision and, very often, to blindness. In diabetic retinopathy, optic neuropathies, and glaucoma, RGC axons degenerate and the cell bodies die. Considering just glaucoma, there are an estimated 1 million people afflicted in France with direct medical costs of 455$969 € /$ patient/year in Europe depending on severity (Traverso et al., 2005). Thus, any factor that might protect against RGC loss and stimulate the regrowth of damaged RGC axons would be of significant therapeutic interest in multiple diseases of vision.
\end{abstract}

Retinal ganglion cell (RGC) axons provide the only link between the light sensitive and photon transducing neural retina and visual centers of the brain. RGC axon degeneration occurs in a number of blinding diseases and the ability to stimulate axon regeneration from surviving ganglion cells could provide the anatomic substrate for restoration of vision. OTX2 is a homeoprotein transcription factor expressed in the retina and previous studies showed that, in response to stress, exogenous OTX2 increases the in vitro and in vivo survival of RGCs. Here we examined and quantified the effects of OTX2 on adult RGC axon regeneration in vitro and in vivo. The results show that exogenous OTX2 stimulates the regrowth of axons from RGCs in cultures of dissociated adult retinal cells and from explants of adult retinal tissue and that RGCs respond directly to OTX2 as regrowth is observed in cultures of purified adult rat RGCs. Importantly, after nerve crush in vivo, we observed a positive effect of OTX2 on the number of regenerating axons up to the optic chiasm within 14 days post crush and a very modest level of acuity absent in control mice. The effect of OTX2 on RGC survival and regeneration is of potential interest for degenerative diseases affecting this cell type. All animal procedures were approved by the local "Comié d'étthique en expérimentation animale n ${ }^{\circ} 59^{\prime \prime}$ and authorization $n^{\circ}$ 00702.01 delivered March 28, 2014 by the French "Ministére de l'enseignement supérieur et de la recherche".

Key Words: axon regeneration; dissociated retinal culture; GAP-43; homeoprotein; optic nerve crush; OTX2; retinal explants; retinal ganglion

Homeoprotein transcription factors are also morphogens with the capacity to transfer between cells and to regulate gene transcription, protein translation as well as chromatin remodeling in a non-cell autonomous way (Di Nardo et al., 2018). Among this family of transcription factors, OTX2 is essential at many steps of eye development, including the differentiation of photoreceptors and bipolar cells (MartinezMorales et al., 2001; Nishida et al., 2003; Koike et al., 2007; Muranishi et al., 2011). In the adult, OTX2 continues to be expressed in photoreceptors and bipolar cells and when the protein's activity is reduced in hypomorph mice there is a progressive loss of photoreceptors and bipolar cells starting

Centre for Interdisciplinary Research in Biology (CIRB), Collége de France, CNRS UMR 7241, INSERM U1050, Labex MemoLife, Paris Sciences et Lettres Research University, Paris, France

+Current address: Univ. Lille, CNRS, UMR 8523- PhLAM- Physique des Lasers Atomes et Molécules, F-59000 Lille, France

¥Current address: BrainEver, 74 rue du Faubourg Saint Antoine, 75012 Paris and Institute of Neurosciences, 320 Yeu Yang Rd, Shanghai 200031, China

*Correspondence to: Raoul Torero Ibad, PhD, raoul.torero@univ-lille.fr; Kenneth L. Moya, PhD, ken.moya@college-de-france.fr.

https://orcid.org/0000-0002-7598-6180 (Raoul Torero lbad)

Funding: This work was supported by Fovea-Pharmaceuticals, and Global Research Laboratory Program Grant $2009-00424$ from the Korean Ministry of Education, Science, and Technology, HOMEOSIGN: ERC-2013-AdG n³39379 and NeuroprOtx: ANR-16-CE16-0003-02.

How to cite this article: Torero Ibad R, Quenech'du N, Prochiantz A, Moya KL (2022) OTX2 stimulates adult retinal ganglion cell regeneration. Neural Regen Res 17(3):690-696. 
at around 2 months of age (Bernard et al., 2014). In RGCs, the Otx2 locus is silent, but the protein can be detected in ganglion cell layer cells in both mouse and human retina suggesting that RGCs take up the protein, most likely from bipolar cells (Sugiyama et al., 2008; Azzolini et al., 2013).

Previously, it was reported that exogenous recombinant OTX2 promotes the survival of damaged adult RGCs in vitro and in vivo (Torero Ibad et al., 2011). In cultures of dissociated adult mouse retinal cells, OTX2 increased RGC survival up to over four-fold compared to untreated cultures. Cultures of purified adult rat RGCS showed that OTX2 acts directly on RGCS to promote their survival. Intraocular injection of $\mathrm{N}$-methyl-Daspartate (NMDA) rapidly kills RGCs and is considered as an acute model of glaucoma. When co-injected with NMDA, OTX2 provides full protection against excitotoxic RGC loss. In addition, OTX2 protects against the loss of visual acuity caused by NMDA injection.

The aim of this study was to directly examine the potential of recombinant OTX2 to promote regeneration of injured axons in vitro and in vivo. Combined with published results (Torero Ibad et al., 2011; Bernard et al., 2014), the present study further demonstrated the interest of OTX2 for promoting the survival of injured adult RGCs suggesting that it may be used in ocular diseases in which RGCs are lost such as glaucoma and optic neuropathies.

\section{Materials and Methods}

\section{Ethics statement}

All animal procedures were carried out in accordance with French national and European directives for the care and use of research animals and approved by the local "Comite d'éthique en expérimentation animale $n^{\circ} 59^{\prime \prime}$ and authorization $\mathrm{n}^{\circ} 00702.01$ delivered 28 March 2014 by the French "Ministère de l'enseignement supérieur et de la recherche".

\section{Preparation of recombinant OTX2}

Recombinant mouse OTX2 was produced and purified as described (Torero Ibad et al., 2011). Briefly, myc-tagged OTX2, with a 6 histidine tag for purification, at the c-terminal was cloned into a pTrac plasmid (Thermo Fischer, France). Transformed BL21Codon Plus RP (Stratagene/Agilent, Les Ulis, France) bacteria were grown overnight at $37^{\circ} \mathrm{C}$ in MagicMedium (Thermo Fischer, France) and the bacteria mass was resuspended with $10 \mathrm{mM}$ Tris, $100 \mathrm{mM} \mathrm{Na} \mathrm{HPO}_{4}$ $20 \mathrm{mM}$ imidazole, $6 \mathrm{M}$ guanidine $\mathrm{HCl}(\mathrm{pH} 8)$. Disrupted bacteria were centrifuged at 40,000 $\times g$ for 30 minutes and the supernatant recovered and loaded on a HisTrap HP affinity column (GE Healthcare, France). Protein elution was carried out with $6 \mathrm{M}$ guanidine $\mathrm{HCl}, 0.2 \mathrm{M}$ acetic acid and dialyzed against $20 \mathrm{mM}$ phosphate, $0.5 \mathrm{M} \mathrm{NaCl}$, and $25 \mu \mathrm{M}$ ascorbic acid. A bacterial extract from an empty vector was obtained with the same procedure.

\section{Adult mouse mixed retinal culture}

Whole retina mixed cell culture was done as described previously (Torero Ibad et al., 2011). Briefly, 8-week-old male adult C57BL/6JRj mice (weighing between $20 \mathrm{~g}$ and $25 \mathrm{~g}$ ) were killed by cervical dislocation, retinas were dissected in $\mathrm{CO}_{2}$-independent medium (Life Tech), enzymatically digested with papain, and mechanically dissociated with a fire polished glass Pasteur pipette. The cells in suspension were diluted to 150,000 cells $/ 0.5 \mathrm{~mL}$ and then cultured on glass coverslips previously coated with poly-D-lysine $(20 \mu \mathrm{g} / \mathrm{mL})$ and laminin $(10 \mu \mathrm{g} / \mathrm{mL})$. The culture medium was neurobasal $A$ medium (Thermo Fischer) complemented with B27 serumfree supplement (Thermo Fischer), 500 mM glutamine, 25 $\mathrm{mM}$ glutamate, $25 \mathrm{mM}$ aspartate, and antibiotic/antimycotic. Recombinant OTX2 or vehicle was added at the time of plating (final concentration between 0 and $3.3 \mathrm{nM}$ ). The cells were cultured for 6 days before fixation in PBS buffered $4 \%$ paraformaldehyde and immunostained for anti-neurofilament 200 (1:200, raised in rabbit, Sigma-Aldrich, St-Quentin Fallavier, France) overnight at $4^{\circ} \mathrm{C}$ and goat anti-rabbit Alexa fluor 546 for 1 hour at room temperature (Thermo Fisher Scientific, Villebon sur Yvette, France). Images were acquired with a Nikon Eclipse E800 microscope with an OPTRONICS Color digital camera (Nikon France, Champigny sur Marne, France) and opened at the proper magnification in Neurolucida $V 7.0$ software (MBF Bioscience, Delft, The Netherlands). Axons from each cell body were manually traced. Measurements of drawn neurites were performed by NeuroExplorer-associated software (MBF Bioscience, Delft, The Netherlands). Three coverslips per condition were averaged.

\section{Culture of purified adult rat RGCs}

Immunopurified RGCs were prepared from adult rat retinas based on (Fuchs et al., 2005). Eight-week-old male LongEvans rats weighing $180-200 \mathrm{~g}$ were killed by $\mathrm{CO}_{2}$ and cervical dislocation, the eyes were removed and retinas were dissected in $\mathrm{CO}_{2}$-independent media as above. Retinal tissue was dissociated with papain and mechanical disruption. RGCs were captured by substrate bound anti-Thy1 (hybridoma supernatant TIB-103, LGC Promochem, Molsheim, France). Cells were plated and recombinant OTX2 or OTX2 buffer as vehicle control was added at the time of plating (final concentration 0 and $6.6 \mathrm{nM}$ ) and cells were maintained for 6 days at $37^{\circ} \mathrm{C}$ in $5 \% \mathrm{CO}_{2}$. Live cells were incubated with $2 \mu \mathrm{M}$ calcein acetoxymethyl ester (Thermo Fisher Scientific, Villebon sur Yvette, France) for 1 hour at $37^{\circ} \mathrm{C}$, and the number of cells with a neurite longer than two soma diameters on three to four coverslips per condition were counted on A Nikon $90 \mathrm{i}$ microscope with a $488 \mathrm{~nm}$ filter. The investigator who was responsible for cell counting was blind to the treatment condition.

\section{Adult retinal explants}

Eight-week-old C57 Bl6 mice or Long Evans rats were killed by $\mathrm{CO}_{2}$ and cervical dislocation. The eyes were removed and retina flattened $\mathrm{RGC}$ side up on Whatman mixed ester cellulose filters (Whatman, 10409770, Sigma-Aldrich, France). One $\mathrm{mm}^{2}$ explant squares were cut with a Mcllwain tissue chopper and the explant/filter squares were placed RGC side down on poly-D-lysine $(20 \mu \mathrm{g} / \mathrm{mL}$ for mouse retina) or polyD-lysine/laminin $(20 \mu \mathrm{g} / \mathrm{mL}$ and $10 \mu \mathrm{g} / \mathrm{mL}$ respectively for rat retina) coated coverslips and incubated in Neurobasal $A$ medium (Thermo Fischer) complemented with B27 serumfree supplement (Thermo Fischer), 500 mM glutamine, 25 $\mathrm{mM}$ glutamate, $25 \mathrm{mM}$ aspartate, and antibiotic/antimycotic. Recombinant OTX2 or protein buffer $\left(20 \mathrm{mM} \mathrm{PO}_{4}, 0.5 \mathrm{M}\right.$ $\mathrm{NaCl}$ ) as vehicle was added at the time of plating (final OTX2 concentration 0 to $56.2 \mathrm{nM}$ as indicated in the figure). After 6 days in vitro, explant cultures were fixed in buffered $4 \%$ paraformaldehyde and labeled with anti-NF200 as above. Explant images were acquired with Nikon 90i microscope, opened in Fiji software (version 2.0.0-rc-15/1.49k) and axons/ axon fascicles emanating from the explant manually traced by an investigator blind to the treatment condition. Total axon/fascicle length per explant was determined with the measure command and averaged for at least four explants per condition.

\section{Optic nerve crush and recombinant OTX2 injection into the eye}

C57 Bl6 male mice weighing $25 \mathrm{~g}$ were housed 4-6 per cage with a 12-hour light/dark cycle and access to food and water ad libitum. Optic nerve crush (ONC) was performed as described (de Lima et al., 2012). In brief, mice were anesthetized by an intraperitoneal injection of ketamine (Imalgène 500, 100 mg/kg Virbac, Carros, France) and xylazine (Rompun 2\%, $10 \mathrm{mg} / \mathrm{kg}$ Bayer). Tropicamide (mydriaticum 0.5\% Thia, France) was used to dilate the iris. The lids of the right 


\section{Research Article}

eye were gently retracted to produce a mild exophthalmia and the conjunctiva was cut with iridectomy scissors along the ora serrata starting at the dorsal pole. The superior rectus was cut proximal to the limitans, the optic nerve adjacent to the globe was exposed by blunt dissection and crushed under visual guidance for 10 secsonds using 5/45 45 -angled jeweler's forceps (WPI). The crush site was visually verified by two investigators, one using a Kaps surgical scope (Pouret Médicale, Clichy, France) and the other via live cell imaging (MediCapture Video System, Pouret Médicale, Clichy, France). The eye was repositioned in the orbit and irrigated with normal saline. Within 5-15 minutes, OTX2 (30-205 ng in 1-2 $\mu \mathrm{L}$ of $20 \mathrm{mM} \mathrm{PO}_{4}, \mathrm{NaCl} 137 \mathrm{mM}, \mathrm{pH} 7.4$ ) or 1-2 $\mu \mathrm{L}$ of the bacterial extract from recombinant protein purification (20 $\mathrm{mM} \mathrm{PO}_{4}, \mathrm{NaCl} 137 \mathrm{mM}, \mathrm{pH}$ 7.4) were injected intraocularly as described (Torero lbad et al., 2011). Since inflammation can have an effect on RGC survival and regeneration (see Discussion), we used the bacterial extract as a control to take into account any such effects of the bacterially produced protein. After eye injection, the mice were placed in a heated chamber at $37^{\circ} \mathrm{C}$ until recovered from the anesthesia and returned to their home cages.

\section{Anatomical analyses}

Two weeks after OTX2 injection, mice were terminally anesthetized and transcardially perfused with PBS followed by buffered $4 \%$ paraformaldehyde, eyes were removed and the dissected retina was prepared with four cuts for flat mount processing and post fixation in buffered $4 \%$ paraformaldehyde. Optic nerves were dissected at the optic nerve head, post-fixed in buffered $4 \%$ paraformaldehyde on a paper filter and prepared for cryosection. Free-floating retinas were processed for Brn3a (Santa Cruz antibodies, sc31984) immunofluorescence and RGCs were counted in eight fields of view per retina using the Fiji software (Danias et al., 2002). Optic nerves were processed using anti-GAP-43, a marker for axon regrowth (Moya et al., 1988). Fourteen micron longitudinal optic nerve sections were mounted on Superfrost slides (Thermo Scientific). Slides were rinsed at room temperature for 10 minutes in Tris buffered saline (TBS; 50 mM Tris, pH 7.4, $155 \mathrm{mM} \mathrm{NaCl}$ ), transferred to $100 \%$ methanol for 10 minutes and washed again in TBS. Blocking was carried out in TBS containing 10\% normal donkey serum (Invitrogen) and 2\% bovine serum albumin (Sigma-Aldrich) for 1 hour at room temperature. Slides were then incubated with primary antibody sheep anti-GAP-43 (1:2000; Leon et al., 2000) overnight at $4^{\circ} \mathrm{C}$. Slides were washed three times and then incubated in the secondary antibody (donkey antisheep Alexa 488, Thermo Fisher, at 1:800) for 2 hours at room temperature. The number of axons at different distances between the crush site and the optic chiasm was counted using a Nikon 90i microscope by an investigator blind to the treatment condition. Confocal images were taken with an A1 Nikon CLSM to illustrate regeneration.

\section{Visual acuity testing}

Mice were tested for visual acuity 1 week before, and 3 and 13 weeks after ONC. Visual acuity was tested using the OptomotryTM (Cerebral Mechanics, Inc., Medicine Hat, Alberta, Canada). Mice were placed on an elevated platform in an arena surrounded by four high definition video screens. Black and white $100 \%$ contrast square-wave gratings of different spatial frequencies were presented in a semishuffled order. In the optokinetic response, mice make head turns in the temporo-nasal direction of the stimulus direction. If the stimulus is clockwise, the head turn is from left to right and driven by the left eye. If the stimulus is counterclockwise, the head turn is from right to left and driven by the right eye. The experimenter was blind to spatial frequency and to the direction of movement presented. If no head turn was signaled within 2 minutes, a pattern of lower spatial frequency was presented. If a head turn was observed, the next higher spatial frequency was presented to establish the acuity threshold. For the final test at 13 weeks, the left, non-affected eye was sutured shut, one day prior acuity testing to avoid any compensation from that eye. The mice were anesthetized with xylazine/ketamine as above, the skin around the eye was swabbed with $70 \%$ ethanol, avoiding to contact the eye and the lid sutured closed with two sutures of $6 / 0$ silk.

\section{Statistical analysis}

Analyses and graphic representation of the results were carried out using Prism 6 (GraphPad Software, San Diego, CA, USA). Single comparisons were carried out by Student's t-test, and multiple comparisons were performed by analysis of variance (ANOVA) and followed by the Fisher's protected least significant difference (PLSD) test for post hoc comparison if justified. Values are reported as mean \pm SEM and results were considered significant at $P<0.05$

\section{Results \\ OTX2 effects on adult dissociated RGCs}

OTX2 stimulated the growth of neurofilament-labeled axons from dissociated adult mouse RGCs in mixed culture (Figure $\mathbf{1 A}$ and $\mathbf{B}$ ). With OTX2, some of the axons were long and tortuous. The measured cumulated axon length per coverslip was significantly increased with OTX2, about doubled at 0.66, 1.65 and $3.3 \mathrm{nM}$ protein compared to vehicle control (Figure 1C). In terms of neuron survival, OTX2 can act directly on neurons in vitro (Torero Ibad et al., 2011; Vargas Abonce et al., 2019). In the mixed culture, OTX2 may act directly on RGCs or indirectly via activity on the other cells present such as bipolar cells, amacrines, Müller glia to stimulate axon regrowth. We used purified cultures of rat adult RGCs to address this question. OTX2 stimulated the growth of neurites from RGCs purified from adult rat retina (Figure 1D and E). We counted the number of live cells and found a significant 5-fold increase at $3.3 \mathrm{nM}$ exogenous OTX2 (not shown). We also counted the number of cells with a neurite with a length at least twice the soma diameter. When normalized to the number of live RGCs, there was a significant 2-fold increase in the number of cells with a neurite (Figure 1F). Since OTX2 increases the survival of RGCs in these conditions (Torero lbad et al., 2011), these results suggest that OTX2 stimulated neurite outgrowth over and above the increase in survival. These results show that exogenous recombinant OTX2 promotes the growth of axons from dissociated adult RGCs from mouse and rat in vitro, and that RGCs can respond directly to OTX2 for fiber regrowth.

\section{OTX2 effects on axon outgrowth from adult retinal explants}

Tissue dissociation shears off axons and dendrites and removes RGCs from their tissue. We then tested whether OTX2 would have an effect on axon growth from explants of adult retina. OTX2 stimulated the growth of numerous neurofilament-labeled axons from adult rat retinal explants. In cultures of vehicle treated explants, axons tended to be isolated and their cumulative length was about $12 \mathrm{~mm}$ in 6 days (Figure 2A and $\mathbf{C}$ ). Explants treated with $13.2 \mathrm{nM}$ OTX2 grew out axons/axon fascicles about three times longer in cumulative length (Figure 2B). This growth is likely to be an underestimate of total growth since this fiber growth included dense bundles formed by multiple axons and thus cumulative individual axon length could be much greater. Substrates of lysine alone compared to lysine/laminin are reported to be less supportive of neurite outgrowth (Yong et al., 1988; Sun et al., 2012). We then wanted to determine if OTX2 could stimulate axon regeneration on a less permissive substrate. The growth of axons from mouse explants cultured on polyD-lysine without laminin was considerably less but OTX2 still increased cumulative axon growth in a dose-dependent manner and at $24.6 \mathrm{nM}$ this increase was by about 10 -fold (Figure 2D). Thus, exogenous OTX2 significantly increases 
RGC axon regeneration from adult retinal explants even under conditions less favorable to neurite outgrowth.

\section{OTX2 stimulates RGC axon regeneration in vivo after ONC}

We then tested OTX2 in vivo after ONC in adult mice. First, we observed that OTX2 injected soon after ONC significantly increased RGC survival. ONC greatly reduced the density of Brn3a-labeled RGCs compared to an intact retina (Figure 3AC). Retinas from mice treated with OTX2 clearly had more labeled RGCs. In terms of numbers, whereas adult C57 BI6 mice typically had about $3300 \mathrm{RGCs} / \mathrm{mm}^{2}$ (Jeon et al., 1998), 14 days after ONC, mice treated with vehicle showed a marked reduction in the number of surviving Brn3a-labeled RGCs with only about one-fifth of that number (Figure 3D). In mice injected with OTX2, the retinas had about a thousand $\mathrm{RGCs} / \mathrm{mm}^{2}$, a modest (66\%), but significant increase in the number of Brn3A-labeled surviving RGCs compared to vehicle (Figure 3D) and about one-third of the number of RGCs in an intact retina.

We then evaluated the effect of intraocular injection of exogenous OTX2 on RGC axons after ONC. OTX2 significantly increased and the number of GAP-43-positive fibers/growth cones in the distal optic nerve compared to vehicle injected mice. Longitudinal sections through the optic nerve (Figure 4A) showed bright GAP-43-labled regenerating axons and what are considered to be growth cones were observed along the nerves of OTX2-treated mice (Figure 4B and $\mathbf{C}$ ). We counted the GAP-43-labled axons along the nerve from the crush site to the chiasm (Figure 4D). Near the crush site nerves from mice in both conditions had similar numbers of labeled fibers (95 for vehicle and 88 for OTX2). In nerves from mice treated with vehicle, the number of GAP-43labeled profiles diminished with distance with 20 axons at 3 $\mathrm{mm}$ from the crush site and 9 axons adjacent to the chiasm (Figure 4D). Starting $1 \mathrm{~mm}$ from the crush site, mice treated with OTX2 started to show a trend to have more regenerating GAP-43-labeled axons. At more distal regions of the nerve, the number of regenerating axons (about 50) was maintained at least up to the optic chiasm, while in the vehicle-treated mice there was a steady decrease along the nerve. The difference between OTX2-treated mice and the vehicle-treated mice was significant starting $1.5 \mathrm{~mm}$ from the nerve crush site and this significant difference continued least up to the optic chiasm 4.5 $\mathrm{mm}$ from the crush site (Figure 4D). These results show that OTX2 increased the number of regenerating axons after ONC in vivo over several $\mathrm{mm}$ during 2 weeks.

We then examined whether OTX2 treatment could restore visual function. Mice were randomly assigned to two groups to receive bacterial extract or OTX2 injection and then be tested for visual acuity (Figure 5). Optomotry showed that the mean peak acuity was $0.35-0.375 \mathrm{c} / \mathrm{deg}$ in each group (Figure 5). At 3 weeks post crush, most mice were blind or showed highly reduced visual acuity (Figure 5; note the change in scale for the $Y$ axis), with 10 mice showing no counterclockwise head movements and two mice responding very poorly. At 13 weeks post crush, the left eye was sutured shut and visual acuity was tested. Four of six mice treated with Otx2 responded to the visual stimuli presented to the right eye, although visual acuity was far inferior to that measured before ONC (note the difference on Y-axis in scale). None of the vehicle treated mice responded to the visual stimuli.

\section{Discussion}

Without manipulation, mammalian adult CNS axons including those of RGCs fail to successfully regenerate after axotomy. An important objective in neurobiology has long been to find conditions, factors or treatments that stimulate adult axon regeneration and restore CNS function. Here we provide evidence that the homeoprotein transcription factor OTX2 stimulates RGC axon regeneration in vitro and in vivo in two rodent species.

Dissociation of the retina is a harsh treatment that shears off RGC dendrites and axons and leads to the death of almost all cells. Here, we now show in cultures of dissociated mixed cells from adult retinas that OTX2 stimulates the regrowth of neurofilament-labeled RGC axons. This length of some individual axons is long and at times tortuous. Mixed cultures include all cell types of the retina. To investigate if the other cell types were necessary for the axon growth activity of exogenous OTX2, we prepared cultures of purified adult rat RGCs. Our results show that RGCs can respond directly to exogenous OTX2. Therefore, Otx2-stimulated neurite regrowth occurs independently of the tissue and does not depend on the presence of other retinal cell types.

Retinal explants avoid separating RGC cell bodies from their proximal axons and dendrites and retinal cells remain in their tissue at least initially. In control conditions, few axons grew out from the edges of the explants from adult retinas during 6 days of culture. OTX2 at $13.2 \mathrm{nM}$ and higher concentration significantly stimulated $\mathrm{RGC}$ axon regeneration. Adult rat explant cultures on laminin/poly-D-lysine grew out axons with a cumulative length of at least $40 \mathrm{~mm}$ in 6 days. The growth from adult mouse retinal explants grown on poly-D-lysine was less, but still significantly increased by exogenous OTX2. This latter result shows that even on a substrate that poorly supports axon regrowth (i.e., poly-D-lysine alone), OTX2 still stimulated significant growth from adult mouse retinal explants.

The observation that higher concentrations of OTX2 were required to stimulate axon outgrowth from the explants compared to dissociated cultures may reflect the bioavailability of exogenous OTX2 to each RGC. In dissociated culture, the RGCs are essentially in a two-dimensional array and soluble exogenous OTX2 could have ready access to all RGCs. In explants, the exogenous protein has to pass through the filter and all the layers of the retina to reach RGCs, so it may require higher concentrations. In support of this, it was previously shown that compared to in vitro conditions, about a three-fold greater amount of exogenous OTX2 injected intravitreally was required to penetrate the thickness of an adult mouse retina in vivo (Torero Ibad et al., 2011). Thus, the difference in effective concentration for regeneration from explants and dissociated cells may at least in part be due to penetration of the OTX2 into the explant tissue to reach RGCs in the GCL.

Optic nerve crush leads to massive RGC death and axon loss. Administration of OTX2 5 to 15 minutes after ONC provides a modest but significant increase (about 60\%) in RGC survival. Previously, it was shown that OTX2 protected RGCs against NMDA excitotoxicity in vivo and the present results add a second model for in vivo RGC neuroprotection by OTX2. More importantly, OTX2 greatly increased the number of GAP-43labeled regenerating axons in the distal nerve. In mice treated with vehicle after crush up to the optic chiasm, only nine GAP43-labled profiles were observed in the distal nerve 14 days after ONC. In contrast, on average 50 regenerating axons reach the optic chiasma in mice treated with OTX2.

OTX2 appeared to partially restore visual acuity to a very low level after ONC. Before ONC, mice had a visual acuity threshold of about $0.375 \mathrm{c} / \mathrm{deg}$. Three weeks after nerve crush, they did not respond to the visual stimulus. After 13 weeks after nerve crush, four out of six mice treated with OTX2 responded to the visual stimuli but at very low visual acuity of about 0.03 c/deg, while none of the vehicle treated mice responded to the stimuli. Since the left eye was sutured closed, we are sure that the responses to the visual stimuli, albeit very weak, were driven by the OTX2-treated eye. A limitation of this experiment is that we were unable to visualize RGC axons. 


\section{Research Article}
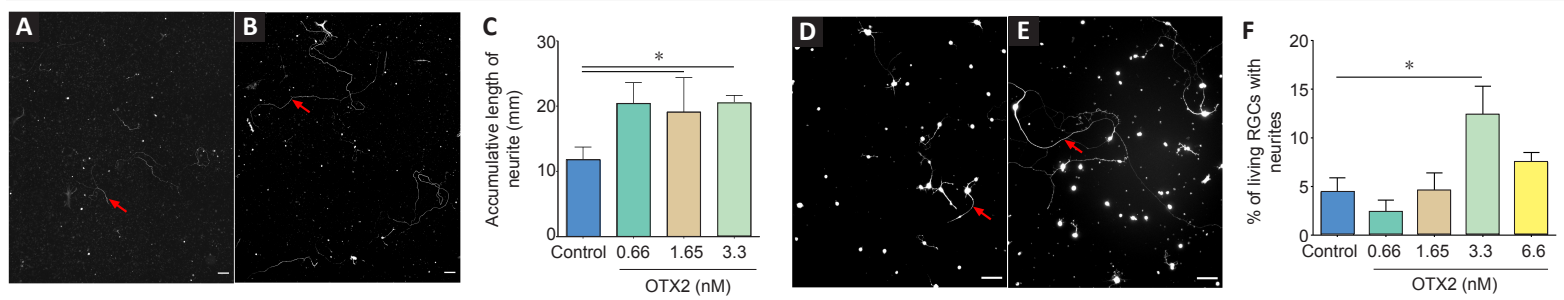

Figure 1 | OTX2 stimulates axon regeneration from RGCs in vitro.

NF-200 immunolabeling dissociated cultures from adult mouse retina shows a few cells with axons (red arrows) after 6 DIV (A), while medium supplemented with OTX2 stimulates long axon regeneration (B). The accumulative length of axon growing from dissociated adult RGCs was significantly increased after treatment with $0.66,1.65$ and $3.3 \mathrm{nM}$ OTX2 compared to control (C). Images of live RGCs purified from adult rat retina show increased neurite growth when treated with $3.3 \mathrm{nM}$ OTX2 (E) compared to control (D). The percent of live RGCs with neurites was significantly greater after treatment with $3.3 \mathrm{nM}$ OTX2 than vehicle (control) (F). Comparisons were made by one-way analysis of variance followed by Fisher's protected least significant difference for post hoc comparisons. ${ }^{*} P<0.05 . n=3-4$ coverslips per condition. Scale bars: $100 \mu \mathrm{m}$. RGC: Retinal ganglion cells.
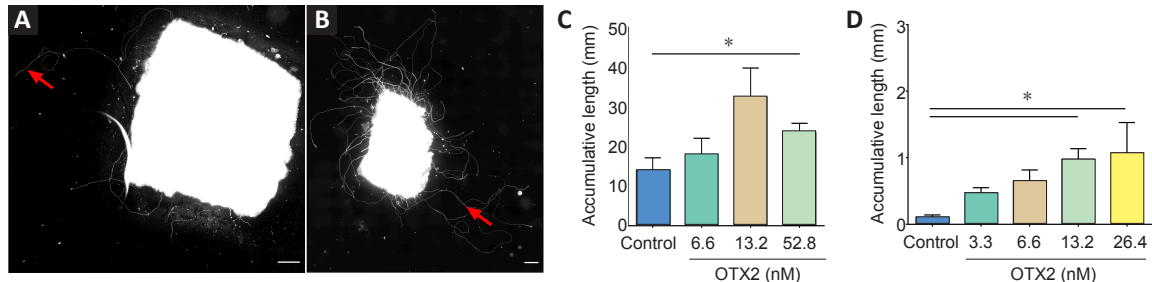

Figure 2 | OTX2 stimulates axon growth from explants of adult retina.

Adult rat retinal explants growing on laminin/poly-D-lysine-coated coverslips and labeled with NF-200 show numerous axons/fascicles (red arrows) when treated with $13.2 \mathrm{nM}$ OTX2 (B) compared to vehicle (A). The accumulative length of the axons/axon fascicles was significantly greater after treatment with 52.8 nM OTX2 than with other concentrations of OTX2 (C). Explants from adult mouse retina cultured on poly-D-lysine alone have much less cumulative axon growth but have significantly more regrowth after treatment with 13.2 and $26.4 \mathrm{nM}$ OTX2 than treatment with other concentrations of OTX2 (D). Comparisons were made by one-way analysis of variance (ANOVA) followed by Fisher's protected least significant difference for post hoc comparisons. ${ }^{*} P<0.05$. $n=4-5$ explants per condition. Scale bars: $200 \mu \mathrm{m}$.
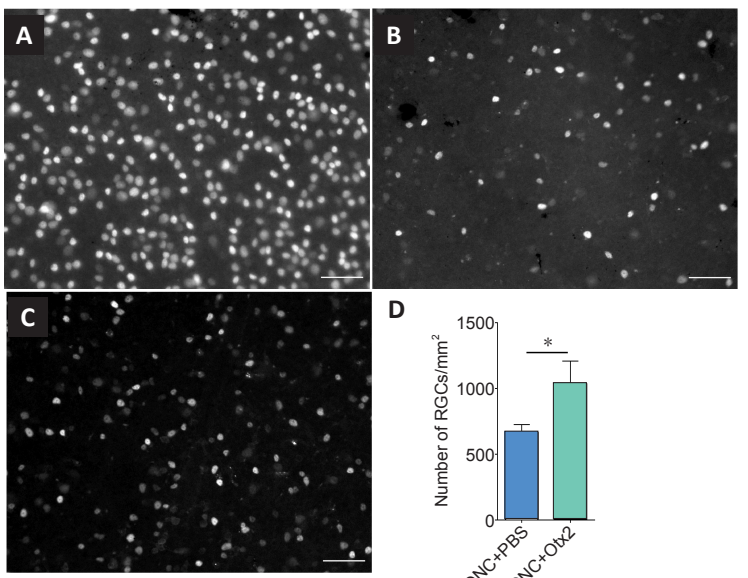

D

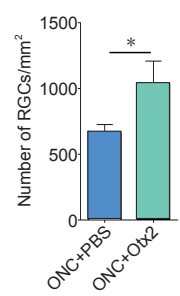

Figure 3 | OTX2 increases RGC survival in vivo after ONC.

Brn3A labeled RGCs of retinal flat mounts in normal adult mouse retina (A), 14 days after ONC in the retina treated with vehicle (B) and 14 days after ONC with intraocular $30 \mathrm{ng}$ OTX2 (C). The images show many fewer Brn3a-labeled RGCs 14 days after ONC (B). There appears to be more labeled RGCs when treated with OTX2 14 days after ONC (C). Scale bars: $100 \mu \mathrm{m}$. OTX2 increased the number of RGCs by about $60 \%$ (D). ${ }^{*} P<0.05$, Student's $t$-test. $n=14$ or 15 mice per treatment. ONC: Optic nerve crush; RGC: retinal ganglion cells.
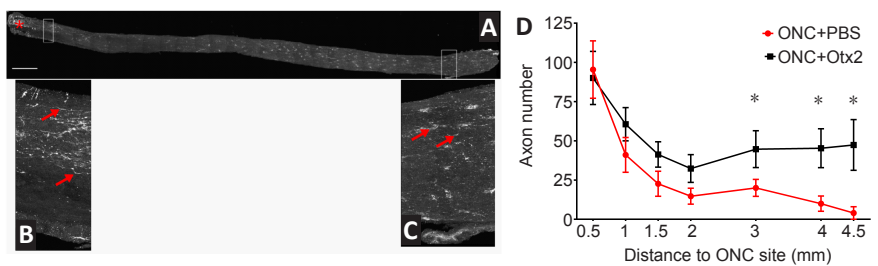

Figure 4 | OTX2 increases GAP-43-labeled regenerating axons in the optic nerve 14 days after ONC.

Optic nerve (A) showing the crush site (red asterisk) and reprenstative images of regenerating axons labeled for GAP-43 (red arrows) at proximal (B) and distal (C) positions. (D) The numbers of GAP-43-positive regenerating axons along the optic nerve 14 days after ONC proximal and distal to the crush site. Starting at $1.5 \mathrm{~mm}$ from the $\mathrm{ONC}$ site, there were significantly more regenerating RGC axons in mice treated with OTX2 (30-205 ng) compared to those treated with vehicle. ${ }^{*} P<0.05$, one-tailed Student's $t$-test. $n=5-14$ per time point per group. Scale bar: $250 \mu \mathrm{m}$. GAP-43: Growth associated protein-43; ONC: optic nerve crush; RGC: retinal ganglion cell.
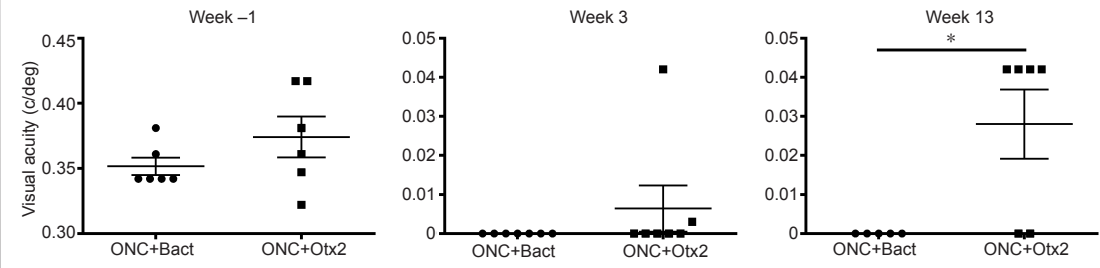

Figure 5 | Optic nerve crush reduces visual acuity and OTX2 partially restores visual acuity.

One week before ONC was about 0.37 cycles per degree (c/deg). At 3 weeks after ONC, visual acuity was diminished to less than $0.01 \mathrm{c} / \mathrm{deg}$. At 13 weeks after ONC, the group treated with $205 \mathrm{ng}$ OTX2 showed visual acuity of $0.3 \mathrm{c} / \mathrm{deg}$ while mice in the bacterial extract control showed no response to the optotype stimulation. Each point represents an individual mouse. Bact: BLil Codon Plus RP; ONC: Optic nerve crush. 
Cholera toxin $\beta$-subunit anterograde tracing did not work and 13 weeks is too late after the elongation period of axon growth for the axons to be labeled with GAP-43 (Moya et al., 1988). Thus, in this experiment, we were unable to quantify how far past the chiasm any RGC fibers reached.

While Otx2 stimulates RGC axon regeneration in vitro and in vivo, is the amount of regeneration meaningful? C57 Blk6 mice have about 50-52,000 RGC axons in the optic nerve (Jeon et al., 1998; Templeton et al., 2014) and these 50-52,000 RGCs and axons underpin all visual behaviors, some of which are complex. Figure 6 compares the number of regenerating axons at their maximal distance after ONC crush obtained with various manipulations in other laboratories. Many strategies resulted in less than 50 axons regenerating to $1-1.5 \mathrm{~mm}$ from the ONC site. Duffy et al. (2012) observed 16 axons reaching 1 $\mathrm{mm}$ in EphrinB3 knockout mice. Brown et al. (2012) reported similar results in mice in which chondroitin sulfate $E$ was removed. To the best of our knowledge, there are only three previous reports of $\mathrm{RGC}$ regeneration reaching the chiasm and only one in the time window that we observed here. de Lima et al. (2012) reported that about 150 axons reached the chiasm 10-12 weeks after ONC after inactivating Pten. Li et al. (2017) used zinc chelation to stimulate regeneration of about 60 axons to the chiasm after 12 weeks. Lim et al. (2016) reported about 180 regenerating axons at the chiasm, 3 weeks after crush, when they enhanced mTOR signaling in addition with high contrast visual stimulation. These approaches are not easily translatable for use in humans.

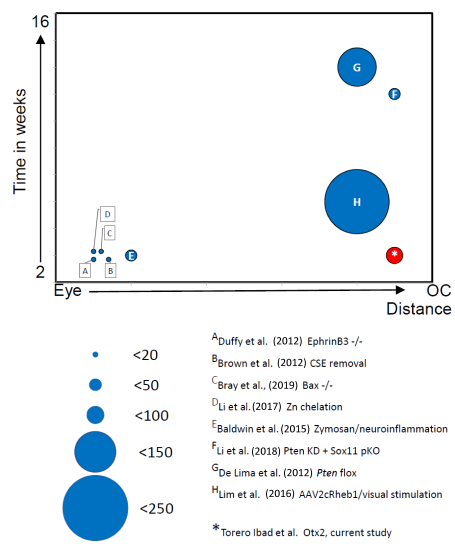

\begin{abstract}
Figure 6 | Comparison of effectiveness of RGC regeneration in vivo. The number of regenerating RGCs is represented by the size of circles. The distance of the furthest regeneration is represented on the $\mathrm{X}$-axis from the back of the eye to the optic chiasm (oc). The time at which the extent of the regeneration was observed is represented along the $\mathrm{Y}$-axis from 2 weeks to 16 weeks after crush. The letters refer to the references listed and discussed in the text. RGC: Retinal ganglion cells.
\end{abstract}

Other recent studies triggering inflammation (Baldwin et al., 2015), using transgenic mice resistant to apoptosis (Bray et al., 2019), altering retinal zinc (Li et al., 2017), combining Pten knockdown with Sox11 knockdown (Li et al., 2018) or overexpressing Lin28 (Wang et al., 2018; Zhang et al., 2019) report that regeneration success rate in terms of number of regenerating axons at the chiasm at 2 weeks after crush was inferior to our results. An important difference in our approach is that we provided additional transcription factor that is already present in the retina without any genetic manipulations.

How does Otx2 increase adult RGC regrowth after injury? One possibility is that the increased axon regeneration may reflect the increase in $\mathrm{RGC}$ survival. In cat retina, adult alpha cells are more resistant to axotomy and appear to be more capable of at least short distance regeneration (Watanabe et al., 1995). The present results could be explained if among the RGCs spared death by OTX2 there are cells corresponding to those resistant to axotomy and/or OTX2 had a preferential effect on regeneration competent cells. In terms of molecular mechanism, Lim28 is of interest because it is expressed in amacrine cells and during development its expression is regulated by OTX2 (Parisi et al., 2017; Zhang et al., 2019). OTX2 is not expressed in amacrine cells of the adult $\mathrm{GCL}$, but all cells including displaced amacrine cells can take up exogenous OTX2 (Torero Ibad et al., 2011). Thus, it is conceivable that OTX2 injected into the eye and taken up by amacrine cells could influence expression of Lin28 and stimulate regeneration. Future studies are needed to explore this possibility.

In addition to promoting significant RGC axon regeneration, OTX2 also promotes the survival of adult RGCs in vitro and in vivo (Torero Ibad et al., 2011) and present results. This might be useful in glaucoma, diabetic neuropathies or neuromyelitis optica. These diseases have been considered axonopathies in which RGC axons start to degenerate due to constriction at the optic head or by autoimmune attack before frank RGC loss (Kern and Barber, 2008; Calkins, 2012; Casson, 2012). In patients diagnosed with such diseases, OTX2 could promote survival of the RGCs, long enough to allow regeneration by OTX2 alone or in combination with another regeneration stimulating approach. One advantage of OTX2 as a possible therapeutic agent is the fact that it is already present in the retina and injecting OTX2 into the eye is simply adding more to what is already present. This obviates the need for gene therapy, cell therapy, or administering compounds that are not endogenous to the human body. Furthermore, the ability of exogenous OTX2 to enter RGCs (Torero Ibad et al., 2011) eliminates the need for vectors or targeting strategies.

A limitation of this experiment is that we were unable to visualize RGC axons. Cholera toxin $\beta$-subunit anterograde tracing did not work and 13 weeks is too late after the elongation period of axon growth for the axons to be labeled with GAP-43 (Moya et al., 1988). Thus, in this experiment we were unable to quantify how far past the chiasm any RGC fibers reached.

Acknowledgments: We thank J. Dégardin and M. Simonutti of the Institut de la Vision (Paris, France) for visual acuity testing and Prof. Larry Benowitz and Dr. Yiqing Li of Boston Children's Hospital (Boston, MA, USA) for assistance in preliminary ONC experiments.

Author contributions: RTI, AP and KLM designed the study, RTI, NQD and KLM performed the study. RTI and KLM analyzed the data. RTI, AP and $K L M$ wrote the paper. All authors approved the final version of this paper. Conflicts of interest: AP and KLM are coinventors for the use of Otx2 in eye disease and cofounders of BrainEver.

Financial support: This work was supported by Fovea-Pharmaceuticals, and Global Research Laboratory Program Grant 2009-00424 from the Korean Ministry of Education, Science, and Technology, HOMEOSIGN: ERC-2013-AdG n³39379 and NeuroprOtx: ANR-16-CE16-0003-02. Institutional review board statement: All animal procedures were approved by the local "Comié d'élthique en expérimentation animale n 59 " and authorization $n^{\circ} 00702.01$ delivered 28 March 2014 by the French "Ministére de l'enseignement supérieur et de la recherche".

Author statement: This paper has been posted as a preprint on bioRxiv with doi: 10.1101/2020.10.06.327999 before submitting, which is available from https://www.biorxiv.org/ content/10.1101/2020.10.06.327999v1.full.

Copyright license agreement: The Copyright License Agreement has been signed by all authors before publication.

Data sharing statement: Datasets analyzed during the current study are available from the corresponding author on reasonable request.

Plagiarism check: Checked twice by iThenticate.

Peer review: Externally peer reviewed.

Open access statement: This is an open access journal, and articles are distributed under the terms of the Creative Commons AttributionNonCommercial-ShareAlike 4.0 License, which allows others to remix, tweak, and build upon the work non-commercially, as long as appropriate credit is given and the new creations are licensed under the identical terms.

\section{References}

Azzolini C, Pagani IS, Pirrone C, Borroni D, Donati S, Al Oum M, Pigni D, Chiaravalli AM, Vinciguerra R, Simonelli F, Porta G (2013) Expression of VEGF-A, Otx homeobox and p53 family genes in proliferative

vitreoretinopathy. Mediators Inflamm 2013:857380. 


\section{Research Article}

Baldwin KT, Carbajal KS, Segal BM, Giger RJ (2015) Neuroinflammation triggered by $\beta$-glucan/dectin-1 signaling enables CNS axon regeneration. Proc Natl Acad Sci U S A 112:2581-2586.

Bernard C, Kim HT, Torero Ibad R, Lee EJ, Simonutti M, Picaud S, Acampora D, Simeone A, Di Nardo AA, Prochiantz A, Moya KL, Kim JW (2014) Graded Otx2 activities demonstrate dose-sensitive eye and retina phenotypes. Hum Mol Genet 23:1742-1753.

Bray ER, Yungher BJ, Levay K, Ribeiro M, Dvoryanchikov G, Ayupe AC, Thakor K, Marks V, Randolph M, Danzi MC, Schmidt TM, Chaudhari N, Lemmon VP, Hattar S, Park KK (2019) Thrombospondin-1 mediates axon regeneration in retinal ganglion cells. Neuron 103:642-657.e7.

Brown JM, Xia J, Zhuang B, Cho KS, Rogers CJ, Gama Cl, Rawat M, Tully SE, Uetani N, Mason DE, Tremblay ML, Peters EC, Habuchi O, Chen DF, Hsieh-Wilson LC (2012) A sulfated carbohydrate epitope inhibits axon regeneration after injury. Proc Natl Acad Sci U S A 109:4768-4773.

Calkins DJ (2012) Critical pathogenic events underlying progression of neurodegeneration in glaucoma. Prog Retin Eye Res 31:702-719.

Casson RJ (2012) Pathogenesis of primary open-angle glaucoma. Clin Exp Ophthalmol 40:838-839.

Danias J, Shen F, Goldblum D, Chen B, Ramos-Esteban J, Podos SM, Mittag T (2002) Cytoarchitecture of the retinal ganglion cells in the rat. Invest Ophthalmol Vis Sci 43:587-594.

de Lima S, Koriyama Y, Kurimoto T, Oliveira JT, Yin Y, Li Y, Gilbert HY, Fagiolini M, Martinez AM, Benowitz L (2012) Full-length axon regeneration in the adult mouse optic nerve and partial recovery of simple visual behaviors. Proc Natl Acad Sci U S A 109:9149-9154.

Di Nardo AA, Fuchs J, Joshi RL, Moya KL, Prochiantz A (2018) The physiology of homeoprotein transduction. Physiol Rev 98:1943-1982.

Duffy P, Wang X, Siegel CS, Tu N, Henkemeyer M, Cafferty WB, Strittmatter SM (2012) Myelin-derived ephrinB3 restricts axonal regeneration and recovery after adult CNS injury. Proc Natl Acad Sci U S A 109:5063-5068.

Fuchs C, Forster V, Balse E, Sahel JA, Picaud S, Tessier LH (2005) Retinal-cellconditioned medium prevents TNF-alpha-induced apoptosis of purified ganglion cells. Invest Ophthalmol Vis Sci 46:2983-2991.

Jeon CJ, Strettoi E, Masland RH (1998) The major cell populations of the mouse retina. J Neurosci 18:8936-8946.

Kern TS, Barber AJ (2008) Retinal ganglion cells in diabetes: Retinal ganglion cells in diabetes. J Physiol 586:4401-4408.

Koike C, Nishida A, Ueno S, Saito H, Sanuki R, Sato S, Furukawa A, Aizawa S, Matsuo I, Suzuki N, Kondo M, Furukawa T (2007) Functional roles of Otx2 transcription factor in postnatal mouse retinal development. Mol Cell Biol 27:8318-8329.

Kong WC, Cho EY (1999) Antibodies against neurofilament subunits label retinal ganglion cells but not displaced amacrine cells of hamsters. Life Sci 64:1773-1778.

Leon S, Yin Y, Nguyen J, Irwin N, Benowitz LI (2000) Lens injury stimulates axon regeneration in the mature rat optic nerve. J Neurosci 20:4615-4626.

Li Y, Andereggen L, Yuki K, Omura K, Yin Y, Gilbert HY, Erdogan B, Asdourian MS, Shrock C, de Lima S, Apfel UP, Zhuo Y, Hershfinkel M, Lippard SJ, Rosenberg PA, Benowitz L (2017) Mobile zinc increases rapidly in the retina after optic nerve injury and regulates ganglion cell survival and optic nerve regeneration. Proc Natl Acad Sci U S A 114:E209-218.

Li Y, Struebing FL, Wang J, King R, Geisert EE (2018) Different effect of Sox11 in retinal ganglion cells survival and axon regeneration. Front Genet 9:633.
Lim JH, Stafford BK, Nguyen PL, Lien BV, Wang C, Zukor K, He Z, Huberman AD (2016) Neural activity promotes long-distance, target-specific regeneration of adult retinal axons. Nat Neurosci 19:1073-1084.

Martinez-Morales JR, Signore M, Acampora D, Simeone A, Bovolenta P (2001) Otx genes are required for tissue specification in the developing eye. Development 128:2019-2030.

Moya K, Benowitz L, Jhaveri S, Schneider G (1988) Changes in rapidly transported proteins in developing hamster retinofugal axons. J Neurosc 8:4445-4454.

Muranishi Y, Terada K, Inoue T, Katoh K, Tsuji T, Sanuki R, Kurokawa D, Aizawa S, Tamaki Y, Furukawa T (2011) An essential role for RAX homeoprotein and NOTCH-HES signaling in Otx2 expression in embryonic retinal photoreceptor cell fate determination. J Neurosci 31:16792-16807.

Nishida A, Furukawa A, Koike C, Tano Y, Aizawa S, Matsuo I, Furukawa T (2003) Otx2 homeobox gene controls retinal photoreceptor cell fate and pineal gland development. Nat Neurosci 6:1255-1263.

Parisi S, Passaro F, Russo L, Musto A, Navarra A, Romano S, Petrosino G, Russo $T$ (2017) Lin28 is induced in primed embryonic stem cells and regulates let7-independent events. FASEB J 31:1046-1058.

Sugiyama S, Di Nardo AA, Aizawa S, Matsuo I, Volovitch M, Prochiantz A, Hensch TK (2008) Experience-dependent transfer of Otx2 homeoprotein into the visual cortex activates postnatal plasticity. Cell 134:508-520.

Sun Y, Huang Z, Liu W, Yang K, Sun K, Xing S, Wang D Zhang W, Jiang X (2012) Surface coating as a key parameter in engineering neurona network structures in vitro. Biointerphases 7:29.

Templeton JP, Struebing FL, Lemmon A, Geisert EE (2014) ImagePAD, a novel counting application for the Apple $\mathrm{iPad}^{\circledR}$, used to quantify axons in the mouse optic nerve. Exp Eye Res 128:102-108.

Torero Ibad R, Rheey J, Mrejen S, Forster V, Picaud S, Prochiantz A, Moya KL (2011) Otx2 promotes the survival of damaged adult retinal ganglion cells and protects against excitotoxic loss of visual acuity in vivo. J Neurosci 31:5495-5503.

Traverso CE, Walt JG, Kelly SP, Hommer AH, Bron AM, Denis P, Nordmann JP, Renard JP, Bayer A, Grehn F, Pfeiffer N, Cedrone C, Gandolfi S, Orzalesi N, Nucci C, Rossetti L, Azuara-Blanco A, Bagnis A, Hitchings R, Salmon JF, et al. (2005) Direct costs of glaucoma and severity of the disease: a multinational long term study of resource utilisation in Europe. Br J Ophthalmol 89:12451249.

Wang XW, Li Q, Liu C-M, Hall PA, Jiang J-J, Katchis CD, Kang S, Dong BC, Li S, Zhou FQ (2018) Lin28 signaling supports mammalian PNS and CNS axon regeneration. Cell Rep 24:2540-2552.e6.

Watanabe M, Sawai H, Fukuda Y (1995) Number and dendritic morphology of retinal ganglion cells that survived after axotomy in adult cats. J Neurobiol 27:189-203.

Yong VW, Horie H, Kim SU (1988) Comparison of six different substrata on the plating efficiency, differentiation and survival of human dorsal root ganglion neurons in culture. Dev Neurosci 10:222-230.

Zhang Y, Williams PR, Jacobi A, Wang C, Goel A, Hirano AA, Brecha NC, Kerschensteiner D, He Z (2019) Elevating growth factor responsiveness and axon regeneration by modulating presynaptic inputs. Neuron 103:39-51.e5.

C-Editors: Zhao M, Liu WJ; S-Editor: Li CH; L-Editor: Song LP; T-Editor: Jia Y 